\title{
Miranda
}

Revue pluridisciplinaire du monde anglophone /

Multidisciplinary peer-reviewed journal on the English-

speaking world

$12 \mid 2016$

Mapping gender. Old images ; new figures

\section{AS - C()n Du It by Katarzyna Giełżyńska - a case of a total translation of an electronic literature work}

Piotr Marecki and Aleksandra Małecka

\section{OpenEdition}

\section{Journals}

\section{Electronic version}

URL: http://journals.openedition.org/miranda/8371

DOI: 10.4000/miranda.8371

ISSN: 2108-6559

Publisher

Université Toulouse - Jean Jaurès

\section{Electronic reference}

Piotr Marecki and Aleksandra Małecka, "AS - C(n Du It by Katarzyna Giełżyńska - a case of a total translation of an electronic literature work", Miranda [Online], 12 | 2016, Online since 01 March 2016, connection on 16 February 2021. URL: http://journals.openedition.org/miranda/8371 ; DOI: https:// doi.org/10.4000/miranda.8371

This text was automatically generated on 16 February 2021

\section{(c)}

Miranda is licensed under a Creative Commons Attribution-NonCommercial-NoDerivatives 4.0 International License. 


\title{
AS - C()n Du It by Katarzyna Giełżyńska - a case of a total translation of an electronic literature work
}

\author{
Piotr Marecki and Aleksandra Małecka
}

\section{Introduction}

1 This paper is devoted to one of the several translation projects the authors have undertaken in the field of electronic literature. As both researchers and practicians we have performed and produced Polish-English and English-Polish translations of works from various genres of e-lit. In these projects, we were responsible not only for translating the textual layer of the work, but also for adapting the code (in generative works), adapting the technical aspects of the publishing process, as well as engaging in PR and dissemination. The translation projects have typically been accompanied by presentations at conferences and festivals devoted to digital media or translation studies. The background for practical and theoretical testing and development of the projects is provided by the NGO and publishing house Korporacja Ha!art, established in Kraków in 1999, which produces conventional and unconventional books, ebooks, audiobooks, experimental films, a magazine and web portal, as well as organizes conferences, events and a festival. Korporacja Ha!art is also a key institution for the development of the theoretical lexicon that is used in discussion about digital literature and art in Poland. Its influential position dates back to 2002, when it organized the Liternet conference, which introduced the subject to Polish critical reflection and academic thought. Since $2003 \mathrm{Ha}$ !art has published about 50 original e-literary works from a number of genres and multiple translations (from the hypertext of afternoon, $a$ story by Michael Joyce to a collection of highly computational poems by Nick Montfort). 
2 Mixing theory and practice is a common strategy in the fields of digital media and electronic literature. It is not uncommon for practice to precede theory, which is later molded on existing works and solutions. This is the case of the work we shall discuss in our paper, which has the form of a technical report - as understood by Nick Montfort's use of this genre of research communication. (Montfort 2013)

3 The output of this project was first presented in Milwaukee, Wisconsin, US during the ELO 2014 conference $^{1}$ where we showed the Polish original (http://ha.art.pl/ gielzynska/) and English translation (http://ha.art.pl/conduit) of $C($ ) $n$ Du It by Katarzyna Giełżyńska, a collection of 30 video/kinetic poems-the first translation endeavor of its kind in the field of electronic literature. What makes the translation project discussed here different from existing approaches to the language transfer of video poems is that it represents a kind of total translation where the translator is responsible not only for the textual layer, but also-if recreating the poem in the target language requires such intervention- for adapting sound,-editing and image. In addition, since from the beginning of the project we knew that, as is often the case with translation of poetry, our endeavor could be deemed "impossible", the main translation was accompanied by an ironic side-project in the form of another experiment involving abusive subtitling, a technique borrowed from the fansubbing subculture.

Our paper is divided into three parts. First, we describe the collection of poems, discuss its status and reception in the field of Polish electronic literature and try to assign it to a (e)literary genre. Next, we present a report on the process of the translation of the volume and provide commentary from the theoretical perspective. Finally, we describe the theoretical assumptions behind the abusive subtitling intervention.

\section{C()n Du It, or the poetics of the logotype}

5 Katarzyna Giełżyńska is a Polish artist, who lives and works in Prague, Czech Republic. When she studied in Poland, her mentor was professor Wojciech Bruszewski, a celebrated visual and film artist. ${ }^{2}$

6 In her professional career Giełżyńska works on a daily basis with text, but it is text in the medium of film. She describes her job position as "motion graphic." In her work for institutions like Czech TV stations or producer companies, she is responsible for the textual aspect of audiovisual works, films, series or advertising campaigns. She designs and/or animates opening titles, closing titles, signs for advertisements, and any other files, where the textual aspect is significant and noticeable, like posters, billboards, teasers, trailers or logotypes. The artist has been dealing with these genres in her everyday work for many years. With these forms she communicates to a large part of the Czech society, for instance, designing Christmas TV campaigns. These kinds of works, in which all aspects of the text are subjected to attracting the viewers' attention and efficiently communicating its message, are a point of departure for Giełzyńska's artistic works.

7 As of the authors' knowledge, the volume $C() n D u I t,{ }^{3}$ is the only published work of electronic literature by Giełżyńska. Her collaboration with the publishing house began when the author sent a video poem to Korporacja Ha!art's 2012 Internetowy Turniej Jednego Wiersza [pl. Online One Poem Tournament] and was invited by the editors to publish an entire collection on its website. Even if the context of the publication of the 
work is an e-literary competition, assigning a genre to the artist's work is a complicated task: on the one hand, the pieces are poetry, textual works drawing from the traditions of concrete and kinetic poetry, but on the other hand, they may also be analyzed as animations, music clips and sound pieces. The history of the reception of the work in Central Europe is testimony of its genre fluidity. The collection in Polish, which was published by Korporacja Ha!art online and on CD in July 2012, was screened at a number of events in Central Europe, including animated film festivals (like the international Animator in Poznań, Poland), film festivals (such as Dwa Brzegi/Two Riversides in Kazimierz), music festivals (Original Source Up To Date in Białystok), e-lit festivals (Ha!wangarda in Kraków), literary festivals (Miasto Poezji/The City of Poetry in Lublin), in galleries (Bunkier Sztuki in Kraków, 1500m2 do wynajĘcia in Warsaw, Meetfactory in Prague), and academic conferences (Institute of World Literature in Bratislava). Together with the translation it was also shown at ELO 2014, E-Poetry 2015 and the 2015 IATIS conference. The collection was also assigned an ISBN number and was submitted on $\mathrm{CD}$ as an entry for important Polish literary awards, although it was not acknowledged by traditional literary circles as a work of literature. The only critical reception that occurred were articles written by scholars specialized in the study of electronic literature. In addition, in 2012 Korporacja Ha!art published a critical chapbook titled The World in Hyper(de)Scription: On the Film-Poems of Katarzyna Giełżynska. The two language versions of Katarzyna Giełzyńska's work have been qualified for Volume 3 of the ELO Collection, which shall be launched in 2016. ${ }^{4}$

8 A common trait for all the works in the collection is their conciseness - the duration of the clips is often about 10 to 20 seconds, the longest one of them lasts 60 seconds. The artist imposes such time constraints upon herself, because she wants the form in which she communicates her thoughts to mimic that of the audiovisual files attacking us on $\mathrm{TV}$, in ads or on billboards. Giełżyńska works with her poems as a marketing team works with a logo, attaching attention to detail, to consistency and precision of font choice, movement and message; creating a meticulously extracted essence, encompassing multiple senses. Just as the authors of logotypes, she references certain areas of culture, where many layers of a sign or slogan may be understood in a number of ways. For instance, in an interview, she explains about the poem Aut or not:

[...] the yellow triangle signifies the eye of God, but also the road sign Caution!, and the label on radioactive materials. In 20 seconds, I wanted to show the resurrection of the Auth-or, referring to Hamlet's dilemma, to be or not to be, out or not. The author or death of the author? Everybody has to choose on their own, just like Hamlet. (Marecki 2012, 15)

Giełżynska's poems speak of Internet rituals, avatar etiquette, trembling before the terror of installing new updates, and the relationship between the user and the virus. Giełżyńska postulates a description of a world that has never been described in Polish poetry in quite the same way. Because she chooses the form of short films (a few seconds long), kinetic serial poetry, the author gives us a high-speed look at the relationship between the digital world and the physical world and the user. Both the content and the form convey this. Giełżyńska's work is in a way a manifesto for describing the posthuman digital world, in which the very choice of the short form of the clip is meaningful. This idea has been compared by the authors of the chapbook The World in Hyper(de)Scription: On the Film-Poems of Katarzyna Gietżynska with a literary project and manifesto postulated by a group of poets in communist Poland, who also aimed at the description of the world they were witnessing. But here, Giełżyńska, first 
and foremost a film editing artist, decided to work not only in text, but also in sound and image. Because many things happen on the screen at once through the use of film language (a combination of text, sound, movement, and montage), this is a kind of multimodal literature. Text, sound and image in movement are inseparable to the artist, who says:

In my work, word, image and sound, this triad, are supposed to harmonize in stereo, none of these elements can be excluded, only in community they create a complete whole, they are interdependent, they complete each other, like in the Holy Trinity. They exist provided they exist together. (Marecki 2012, 16)

Conciseness together with multimediality not only characterizes the artist's method, but is also well suited to the description of the kind of world on which she focuses. Giełżyńska chooses very minimalist aesthetics, with references to 8 bit graphics and pop-art, as well as films and film posters, graphics, computer games (especially retro shoot'em up games), digital genres, Internet media poetics. According to her, they now define our way of being and expressing ourselves. With these tools, she enters into a polemic with what she sees as an overtechnicized world in which subjectivity dissolves.

In Giełżyńska's words:

The problem that I deal with in the $C() n$ Du It collection is that of the subject, the problem of the author, that is the problem of the "I". We are what we have read, we are made up of quotes. In the web, what is "mine" is illegible, blurred; the other creates us, we live only thanks to the other, otherwise we don't exist. One protects one's individuality, one's "I", which is threatened online. This is why in my poetic animations, verbs appear in the first person singular, as "I", "I click", "I want" together with verbs in imperative mode, embodying the Web that constantly demands something from us: “update!", “click!”.(Marecki 2012, 13)

As already mentioned, these logo-poems rely on minimalist style, aphorism, metaphor, ellipsis and allusion. These elements are the key elements of their poetics. In this sense, Giełżnńska's poems detach themselves from the meanings of words and fluidly transcend to the level of concrete poetry, to which the artist directly refers. The words and characters gain a new life, not only textually, but also visually. In such an understanding every pause, every rhyme conveys meaning. For instance, some parts of the clip Lekcja historii (History lesson) are unreadable for the viewer-reader, because they flow to quickly, which itself becomes a signifying element, tied to the medium in which the poems are made.

13 All the discussed characteristics of Giełżyńska's poems - their medium-specificity, brevity, ambiguity and affinity with concrete poetry on the one hand and with advertising clips on the other hand - affected the choice of translation strategy and the translation process.

\section{C()n Du It in English, or a total translation}

14 It may be postulated that the characteristics that Giełżyńska's pieces have in common with advertisements-immediacy, succinctness and the ability to signify multiple meanings with little words-constitute their dominant poetic characteristic. Thus, if the goal of the translation is to provide the target language viewer with a nearidentical experience of the poetry, the translation strategy must be focused around the preservation of this dominant characteristic. Explaining the multiple meanings in 
subtitles would be like explaining a joke- perhaps it would get the meaning across, but it would kill the effect in the process.

To find a solution for the translation of video poems, one may look at the strategies used in the realm of commercial audiovisual media. Most literature on audiovisual translation distinguishes between two strategies-subtitling and dubbing, sometimes also mentioning the Eastern European curiosity that is voiceover. Of the main two, the first is most often used in translations of the more artistic audiovisual products, since dubbing is seen as more "domesticating", while subtitling lets the viewer also hear the original track, not letting them forget they are experiencing a foreign-language production. Subtitling is also more cost effective, which is an important factor when translating for a smaller audience. However, for the reasons mentioned above, neither of the strategies would be suitable in the context of Katarzyna Giełżyńska's multimodal kinetic poems. Traditional subtitling would kill the puns and double meanings, lose the concrete poetry, fail at getting across the experience where the original text is semilegible or scrolling too fast to read, and would have to be accompanied with more extensive commentary under the video in order to explain some of the visual elements. Dubbing, voiceover or any kind of translation close to audiodescription would also be out of question, for the same reasons, and also due to the need to preserve sound effects. Yet the mainstream audiovisual market has one more strategy to suggest-one which involves interventions in all the layers of the audiovisual work-not only the text (written or uttered), but sometimes also in the image, sound effects and editing. This strategy is localization. Interesting examples of localization can be found not only in advertising, but also in animated movies for younger audiences, who cannot be expected to show patience for the imperfections of language and cultural transfer. For instance, in the Japanese version of Pixar's recent movie Inside Out, there is a scene, in which a pertinent detail was changed. The film is centered around the theme of the five basic human emotions. The scene in question showcases the feeling of disgust, with a little girl frowning when confronted with broccoli. The translation problem encountered by the animation studio is that the food children are picky about is different in various cultures-and Japanese children would not understand why the girl in the film is frowning, as broccoli brings no such associations in that part of the world. Thus, the sequence was reanimated with green bell pepper, which in turn tends to be disliked by the young Japanese, replacing broccoli. ${ }^{5}$ The effort made by the studio was motivated by the will to make the film as enjoyable and meaningful for audiences from different cultures.

Such translational maximalism was applied also in the translation of $C() \mathrm{n} \mathrm{Du}$ It- the decision was made to recreate the poems in the English language from scratch, changing not only the text, but also the image, sound and editing where necessary, with a similar goal as in commercial translations-reaching the viewer as smoothly as possible.

Before we discuss the translation process, we should mention that one of the many unusual things about the discussed translation project is the very direction of the language transfer. It seems that, as in the realm of audiovisual products, in the field of electronic literature, the majority of translations occur from the dominant language and not into it. This problem was noticed by Nick Montfort, who has founded the Renderings lab, which focuses on the translation and porting of works from different languages into English and online in order to broaden and enrich the knowledge of the 
history and variety of electronic literature in different language communities. ${ }^{6}$ The translation of $C() n D u$ It slightly precedes the founding of the lab at MIT, and has a similar goal. It is meant to curate the work of a Polish artist as attractively as possible to make it easily and pleasantly accessible, and thus let it have a better chance at reaching an international audience.

The idea to translate Katarzyna Giełżyńska's poems was proposed by Piotr Marecki in December 2013. The poems were to be featured in the Media Art Show at the ELO 2014 conference and Piotr Marecki suggested an English version would help the international audience at the conference appreciate the poems more fully. The translation of the volume was performed collaboratively by a team that included the translator-Aleksandra Małecka, an English language proofreader, the film editing artist-Katarzyna Giełżyńska, as well as, in the later stage, the administrator of the publishing house's website. The translation method was worked out in the process. The first intuitions were that "the textual elements in the films should be replaced with English equivalents" and a separate web address with an interactive English language menu would be needed to store the whole volume. Katarzyna Giełżyńska noted that such simple replacement of the elements of the animations would not be possible in some cases, because of different word lengths. She also expressed the will to improve some of the clips. Work started in April 2015, when Aleksandra Małecka drafted the Polish-English translations of the text of the poems, accompanying them with notes, ideas and instructions for audiovisual solutions. During the preparation of the translation she consulted the author on the content of the poems, especially where the text was illegible. The team searched for solutions to problems and also for multimedia files, like stock sound samples, if such were needed for the remade versions. The final drafts were corrected by the proofreader. In May 2014, after the textual solutions were proofed and approved, Katarzyna Giełżyńska edited the clips. It turned out that it was a true remake, since the artist had lost her hard drive between 2012 and 2013, and had no original files to work with. Thus, occasionally, she spontaneously decided to include different graphics or motion solutions in a poem, not necessarily because it was required by the translation, but, a year having passed, she had new ideas about the work, which she was redoing from scratch anyway and wanted to improve it or change the animation altogether. She would send the clips one by one for another proofreading. The files were then uploaded to vimeo. They could not be heavier than $500 \mathrm{mb}$. To complete the project, the website with the list of contents menu of the volume was redone in English. Katarzyna Giełżyńska added new graphic materials with English poem titles, which were then linked to the videos on vimeo. The whole project was finalized a few days before the conference. 
Illustration 1

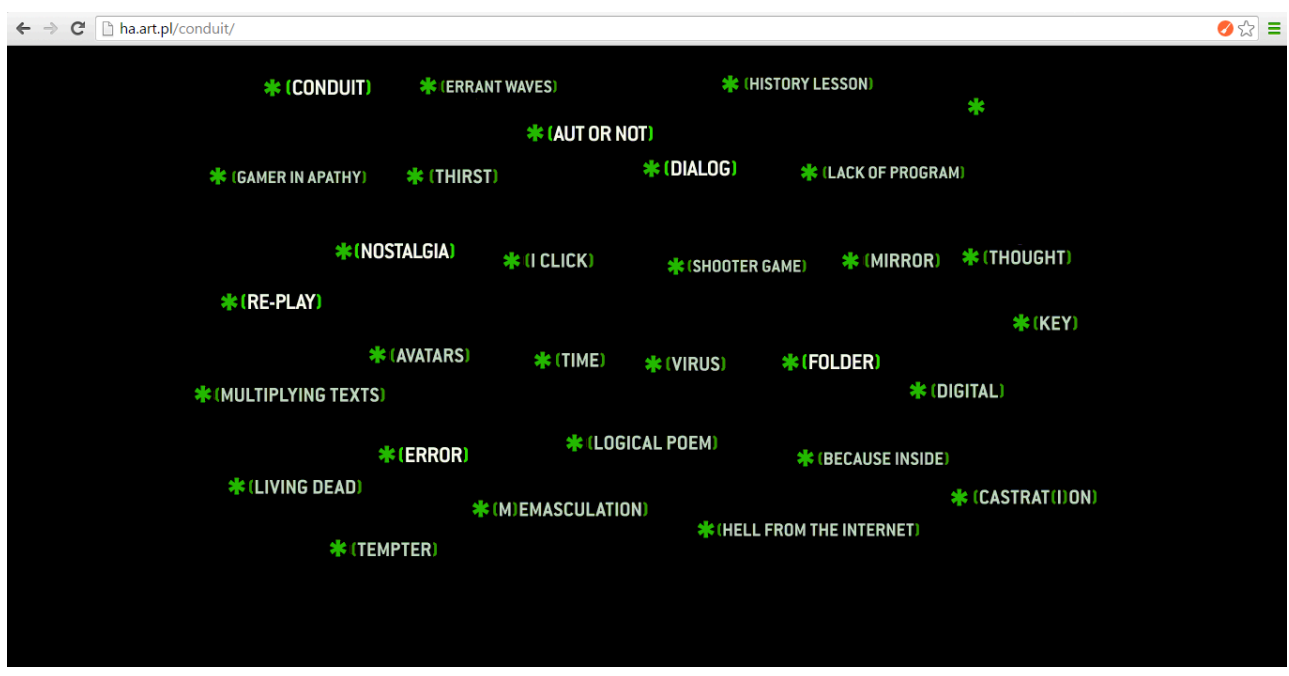

The English translation of the collection of poems is an independent whole. Three poems from the Polish collection-Element, Tkanina and Tablice- were not included in the translation. The decision to omit them was dictated by the fact that at the time the project was being finalized the team did not find satisfactory equivalents for the multimodal puns in these particular pieces and thus decided to leave them out until solutions were found. However, the English volume has one additional poem that was not included in the original set, Living Dead and a double translation of the poem Kastracja-Castrat(I)on and (m)emasculation.

The language transfer of different poems required varying degrees of intervention in the text, sound and image layers. Some of them were left completely unchanged, like the title poem, $C() n$ Du It. Other translations could be called "word for word" ones-the text was translated as it would be in a traditional poem, the sound and image left unchanged. For instance in the poem Nostalgia, both language versions use the idiom "like water off a duck's back" and have the image of ducks in the background. Naturally, translations of clips featuring rhymes, puns or other poetic devices encountered also in traditional poetry faced the translating team with the habitual challenges of literary translation. 
Illustration 3a, 3b, 3c
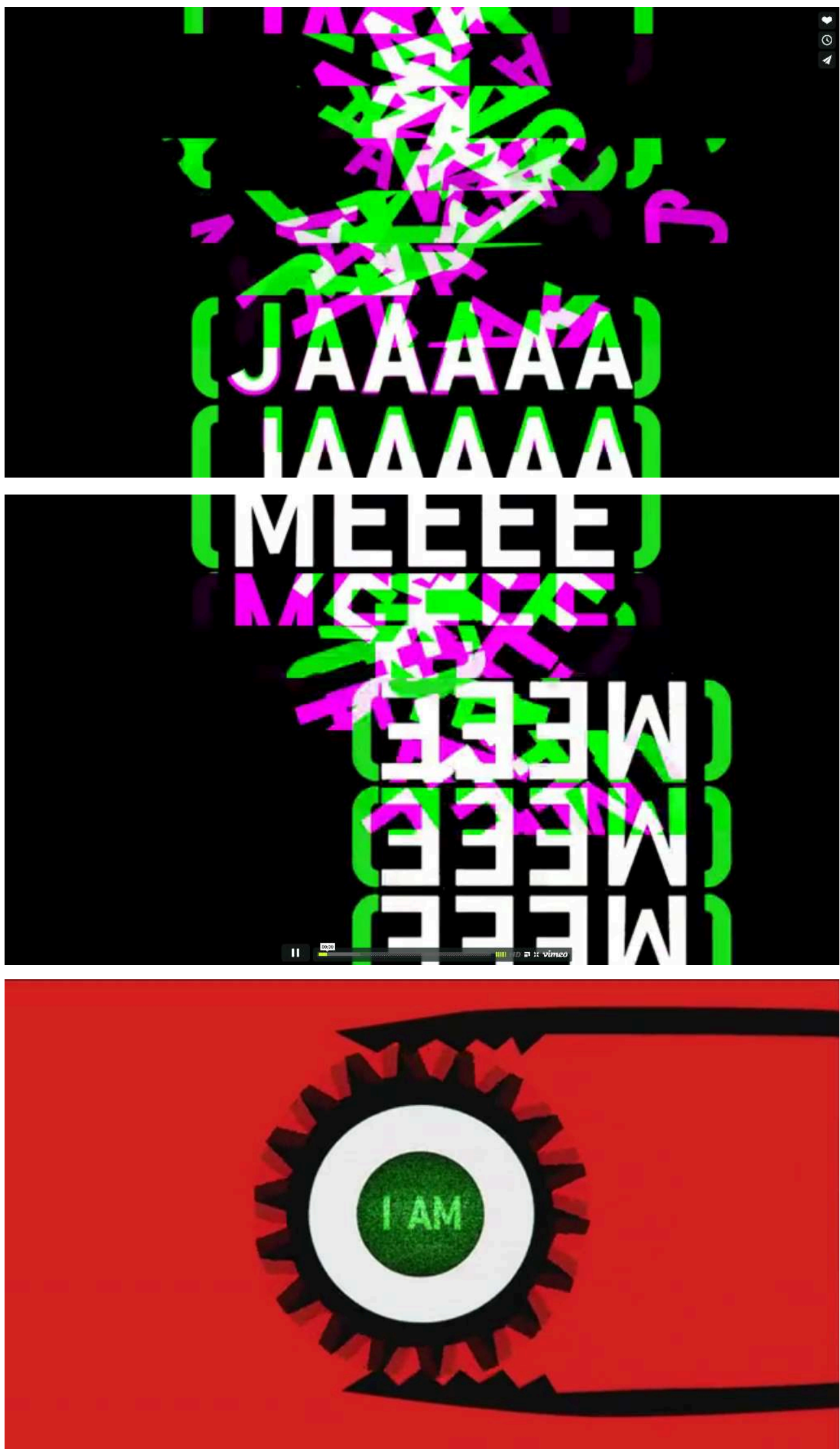
In the case of some other poems, wider intervention was needed. For instance, in the poem Kastracja, the translation of the text required the sound to be adapted too. The short clip is made of animated text of the scream "jaaaa", "ja" meaning "I" or "self" in Polish. It is accompanied by a loud "aaaa" scream. The scream "aaaa" echoes the sound of the vowel in the word "ja." In the translation, if the word "me" is used without substituting the sound layer, it will cause a feeling of dissonance in the viewer. Thus, the translated version titled $(m)$ emasculation was equipped with a soundtrack that sounds more like the phoneme [i:].

The alternative translation of the poem, Castrat(I)on, is, in turn, completely different. It shows the words "I am" in the center of an eye, which starts spinning like the blade of a chainsaw, and them dissolves into green light, without any screams. The careful observer will notice that the eye is a visual borrowing from the poster for the Clockwork Orange film. The wordplay in the title of the translation follows that of the original, the audiovisual layer is completely different. This translation is at the more dynamic end of the scale.

Illustration $2 a, 2 b$
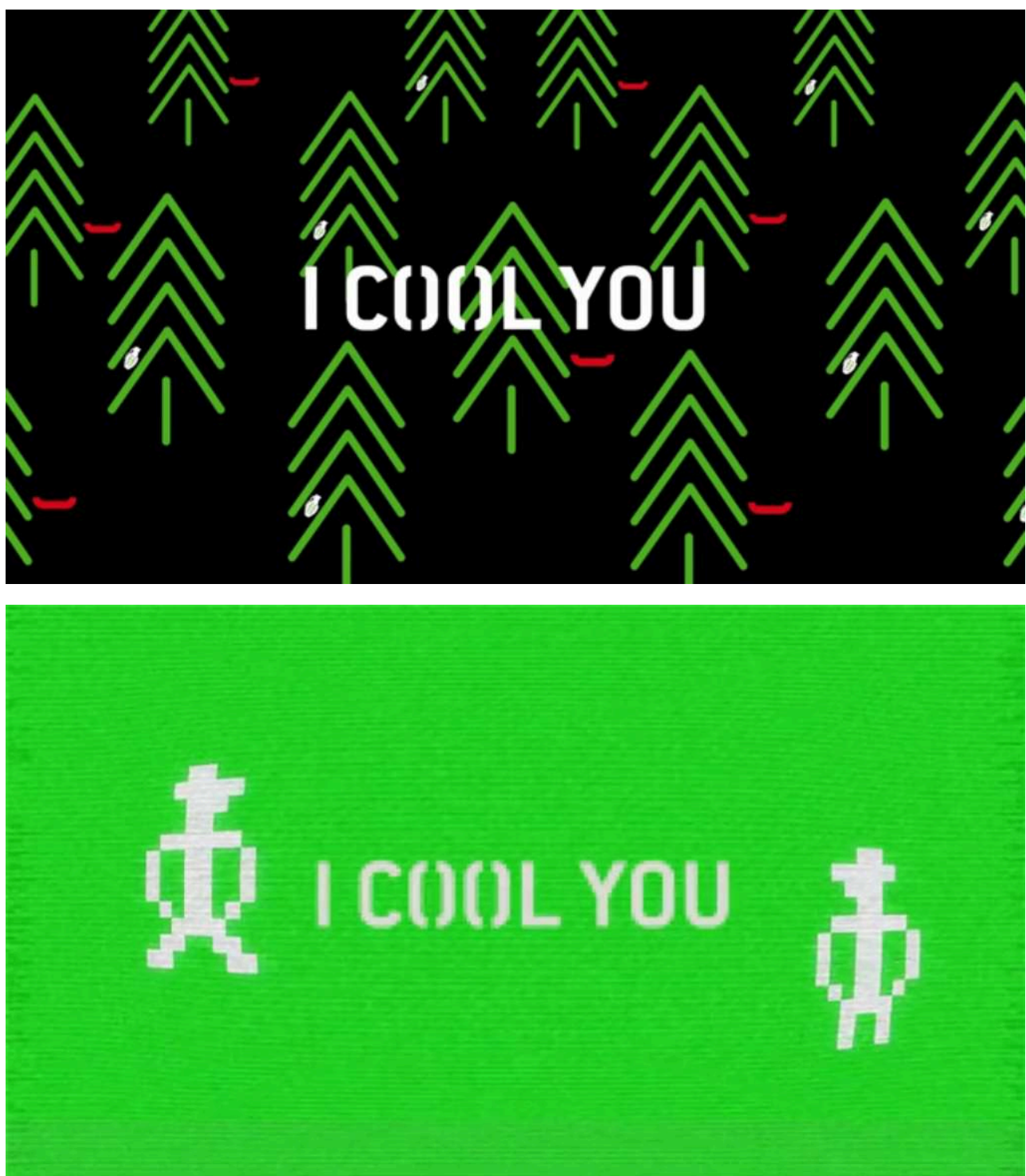
Another poem, which is a very clear case for the necessity of changing all the layers of the poem in order to preserve its essence, is Granaty, translated into English as Shooter game. The original poem, borrowing graphics from an old arcade game, is centered around a pun on the word granaty, which means "grenades." The word explodes and falls apart into the phrase "grana ty" - the meaning becomes "you are being played", the addressee being identified as female. The sense is reflected by the visual layer, which shows falling explosives. Thus, in the English version, a similar pun based on a word related to military activities found in games, dividable into two other meaningful words, had to be invented. The final result invokes a retro shooter game, with two low resolution figures shooting at one another and the word "shooter" falling apart into the phrase "shoot 'er."

24 A poem which required a different kind of conceptual redoing was Hell from the Internet, which features part of a screenshot from Google autocomplete suggestions for searches beginning with the word piekło, which means "hell" in Polish. Instead of translating the Polish search results word for word, the collaborators tested out the search suggestions for the word "hell" in English. Finally, the suggestions from Katarzyna Giełzyńska's browser was chosen (this situation could be seen as interesting in the context of the debate about the relationship between the author and the translator).

Some of the above translation solutions could be perhaps considered unorthodox or unusual by a more conservative translation critic. However, they occur in the very field of experimental literature, where due to the relative novelty of the discipline, its fast development and multiplicity of genres, there are yet no strict translation norms and perhaps never will be.

\section{Abusive subtitling as a commentary to impossibilities of translation}

An often-repeated maxim is that good translation is invisible. This especially pertains to audiovisual products. For instance, Díaz-Cintas writes: "there is a widespread belief that the best subtitles are the ones that are not noticed". (Díaz Cintas 2010, 346) A translated film should be relatively easily processable, like the translations of Giełżnńska's poems described above. In the realm of literary translation, the notion that a translator should be above all "invisible" was challenged in 1995 by Lawrence Venuti in his book The Translator's Invisibility, which resonated widely in the field of translation studies and has since then entered the canon of literature in translation theory (Venuti 2008). However, in the domain of commercial audiovisual translation, the notion that the best translations are ones that are "unnoticeable" still seems taken for granted by most practitioners and critics. This was challenged in the late nineties by Abé Markus Nornes, who calls the normative subtitling practice "corrupt," as it "smooths over its textual violence and domesticates all otherness while it pretends to bring the audience to an experience of the foreign". (Nornes 2011, 17) He claims that constraints are faced by any translator, giving the example of poetry, and there are no excuses for what he calls "violent appropriation." According to Nornes, audiovisual translators should acknowledge the inherent corruption of their practice and become abusive towards it-he urges them to side with the source text, experiment with font position and color, insert footnotes, etc. Examples of "abusive subtitling" were found by Abé Markus Nornes in the Japanese fansubbing subculture, where he observed the 
phenomenon involving the use of subtitles which are "unsuitable" for the content of the film. He described it as an example of an experiment in both linguistics and graphic arts. The academics who have covered this phenomenon are unanimous in indicating the reason why it developed: it opposes the necessity of transferring meaning from the original to another discourse and another construct of reality. Abusive subtitling is also generally a response to an ideological transfer. It comes as no surprise that this phenomenon emerged in film, as this is "transfer" in both a cultural sense and an attempt to translate the medium. Abusive translation is also a form of visible translation, imposing itself on the viewer and thus problematizing translation as such.

As we mentioned earlier, there are no rules in translating electronic literature; moreover, in many genres, translating digital works involves finding a concept, and even rules for various works or groups of works. In general, the translation of a digital work means translating not only the text, but also the code, and often the media or technological platform in whose framework the piece was created. Translation is often as much an experiment as the original work itself. Thus, for Katarzyna Giełżyńska's collection $C() n D u I t$, apart from the English translation of all the work's components (graphics, fonts, montage, text speed, type size), which is an example of an "invisible" localization, a second method was adopted, borrowing from the abusive subtitling subculture. ${ }^{7}$ Other inspirations included the desire to show the original, Polish version to an English-language audience (unaltered by translation) and the will to experiment and play, often problematized in Giełżyńska's poem-films.

In translating Gielżyńska's poetry, not all of the capabilities of abusive subtitling were used, in terms of the graphic opportunities they provide, the color diversification, the play on images. The idea was very simple, and thus its minimalist execution was to be simple as well, pasting ordinary text into the poem (much like what occurs when subtitles are added to films). Abusive subtitling was also a response to the violence performed on the original when translated into English. 


\section{Illustration 4a. 4b. 4c. 4.d}

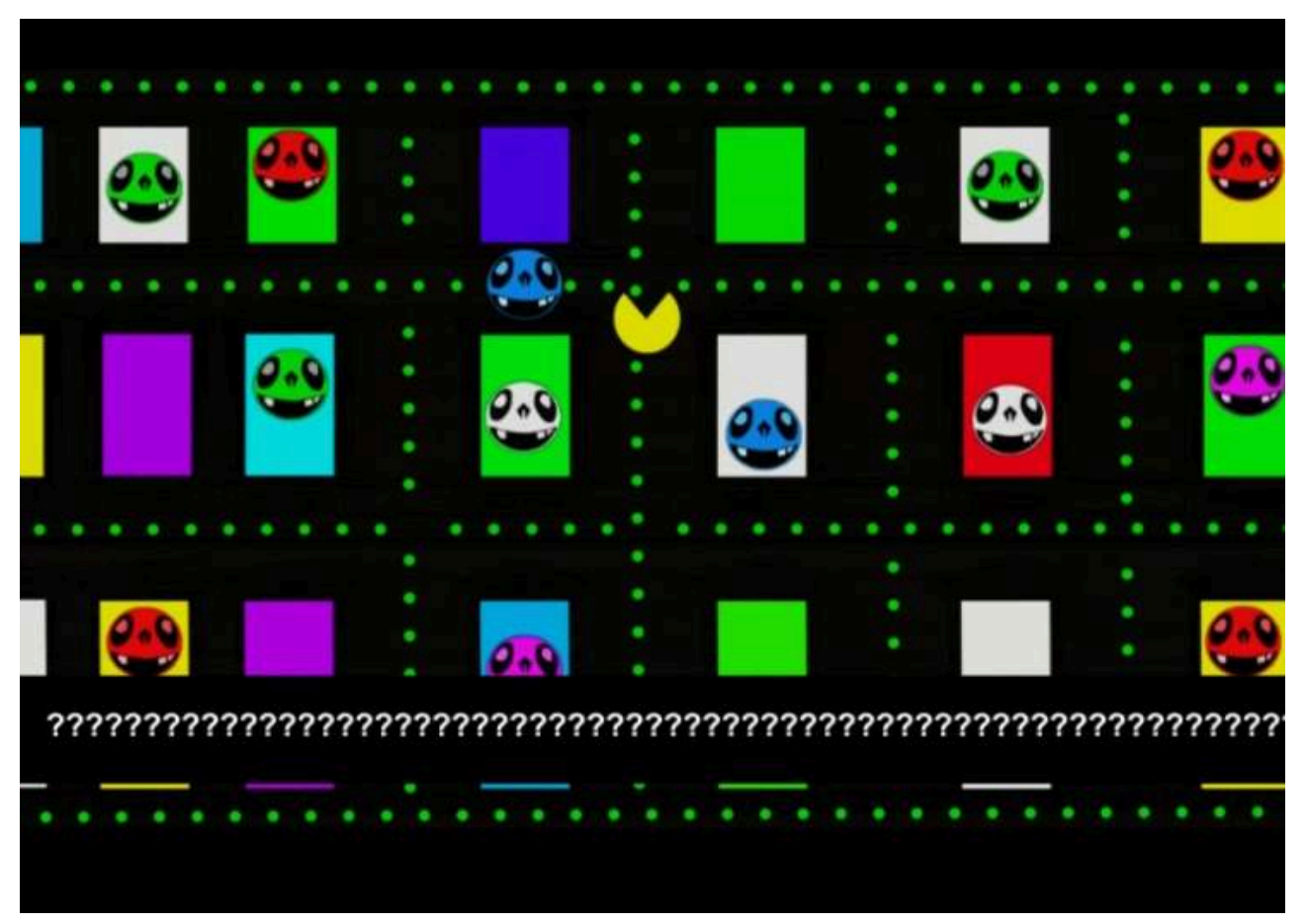

Lyric "I" doesn't appreciate posthumanism, conceptualism, avant-garde, and also highly computational creative works in poetry. What crap. STFU!!!!! Nobody gives a flying fuuurick!!!! This is waaay behind the times.

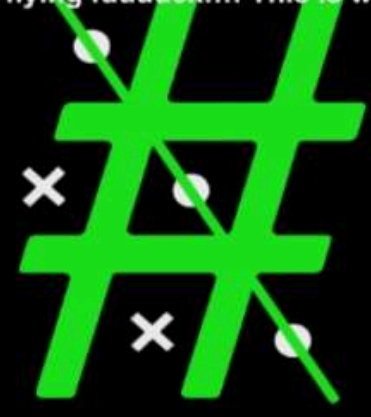



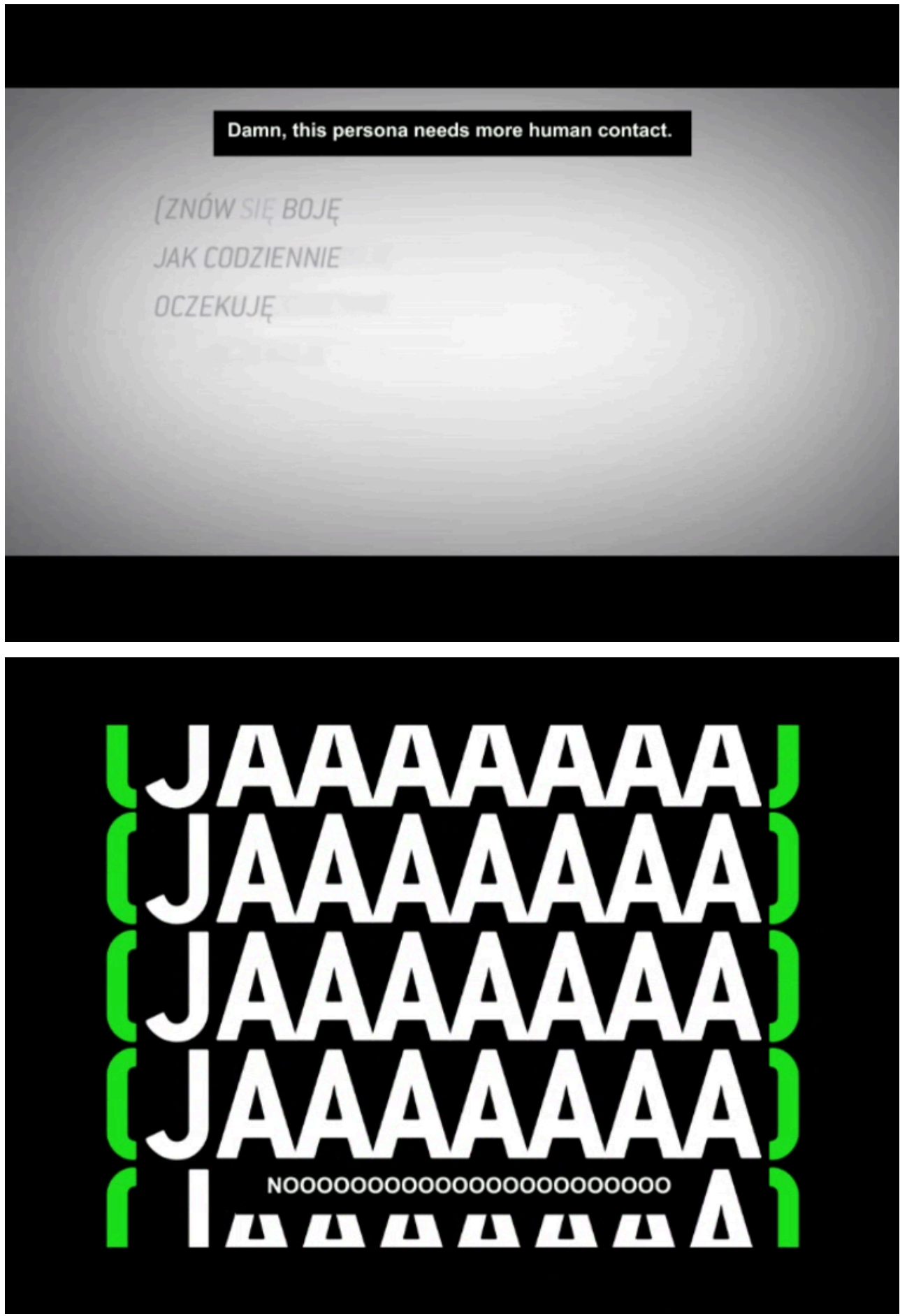

29 Abusive translation in Piotr Marecki's interpretation involves pasting subtitles onto a poem in the form, style, and aesthetic of Internet comments written by anonymous users/avatars under particular articles, or a work published on the Net. It is often written in the poetic of an extreme "hate." The idea of translating a few poems this way was carried out in a twofold manner; on the one hand, Giełżyńska's texts in their English version were presented to four people at the MIT campus who were not much exposed to digital poetry, and who were asked for abusive commentaries. They were students of Comparative Media Studies/Writing MIT, who wanted remain anonymous. The students were asked to express themselve without inhibitions. They were told they 
could use slang and swearwords. Then, Piotr Marecki mixed these comments with random trolling and hating comments from various Internet portals, with typos etc. These commentaries were written down and patched into the poem as a part of it and as violence upon it.

The poems themselves are presented in two ways, both of which abusive, quite visible, and attention-grabbing, a kind of visual assault on the poem. For the reader with no knowledge of Polish, the insult runs even deeper, as he can only understand the English text, which has nothing in common with the Polish. In these subtitles the "constrained" aspect is in that text most often comments on text (unlike in film, where we see the actors, their statements, facial expressions, and body language). Only the font used by the author sometimes changes into figurative action.

Giełżyńska's serial poetry adopts two poetics of incorporating subtitles. On the one hand, this is a method we might call "serial" (which more or less corresponds to the role of subtitles in film): the synchronization of text with various parts of the poem, as in History Lesson, where the phrase 'What the fuck are helicopters from Apocalypse Now doing here?" appears when the viewer/reader sees quotes from Coppola's film on the screen. In turn, the phrase "In the end we're not even able to go about reading it, let alone translate it," explains a serial poetry technique, i.e., the montage speed of the text which the viewer is unable to read (a kind of distracted reading). Another method of laying out the text was placing a few sentences that dominated the screen in the flow of a short original work. This is what happens, for instance in Logical Poem, which contains the fairly elaborate (as abusive commentaries go) confession: "The lyric "I" doesn't appreciate posthumanism, conceptualism, avant-garde, and also highly computational creative works in poetry. What crap. STFU!!!!! Nobody gives a flying fuuuuck!!!! This is waaay behind the times." Or in the poem "Castration," where an expressive N00000000000000000000000 pertains to the title, visualized through the font and the sound.

This pioneering use of abusive subtitling in translating digital literature can be seen as a kind of experiment and a point of departure both for theoretical reflection and for further experiments, bringing digital works to other cultural contexts. Giełżyńska's short poems inspire playfulness, and we see the subversive subtitles as a kind of entertaining translation that has nothing in common with serious translation as such. Or perhaps it does?

\section{Conclusion}

The discussed translation project was an endeavor both in translation practice and theory. The authors wanted to challenge ideas about what translation may and may not be, and also provide commentary through a side project intervention with abusive subtitling performed at the opening of the Hold the Light ELO conference in Milwaukee. Artistic intuition and practice preceded theoretical lexicon. Electronic literature as a field of artistic practice is still relatively young. The field's institutions were founded in the 1990s with the establishment of the Electronic Literature Organization, which initiated a regular exchange of artistic and scholarly practices and experiences during conferences and festivals. Due to the fact that digital media and most internationally recognized e-literary productions are dominated by the English language, inquiries into translation from dominated languages appeared rather recently. Our project was a 
pioneering endeavor in practice, the result of which was a complete and innovative translation taking on new challenges in the field of e-lit translation. Our paper and technical report in one are our contribution into mapping this area of e-literary practice and scholarship.

\section{BIBLIOGRAPHY}

Artistic works:

Katarzyna Giełżyńska, C()n Du It, Kraków: Korporacja Ha!art, 2012. <http://ha.art.pl/gielzynska/>. Katarzyna Giełżyńska, $C()$ n Du It, translated by Aleksandra Małecka, Kraków: Korporacja Ha!art, 2014. < http://ha.art.pl/conduit>.

Katarzyna Giełżyńska, $C($ n Du It, abusive subtitling by Piotr Marecki, performance ELO Conference Hold the Light, June 18-21 2014, Milawukee, Wisconsin, US.

References:

Díaz Cintas, Jorge. "Subtitling” In Handbook of Translation Studies Gambier Y \& Doorslaer Van L, (eds.), Vol. 1. Amsterdam/Philadelpia: John Benjamins, 2010. 344-349.

Marecki, Piotr. "The World Must be described: interview with Katarzyna Giełżyńska" In The World in Hyper(de)Scription: On the Film-poems of Katarzyna Gietżyńska, Marecki, Piotr \& Pisarski, Mariusz (ed.). Kraków: Korporacja Ha!art, 2012. 11-19

Marecki, Piotr \& Pisarski, Mariusz (ed.) Obsessive Anticipation, Kraków: Korporacja Ha!art, 2013. [Accessed: 10.12.2015] <http://www.ha.art.pl/wydawnictwo/nowe-ksiazki/3153-anticipatoryobsession>.

Marecki, Piotr \& Pisarski, Mariusz (ed.). The World in Hyper(de)Scription: On the Film-poems of Katarzyna Giełżyńska, Kraków: Korporacja Ha!art 2012. [Accessed: 10.12.2015]

<http://www.ha.art.pl/wydawnictwo/nowe-ksiazki/2679-the-world-in-hyperdescription-on-thefilm-poems-of-katarzyna-gielzynska>.

Montfort, Nick, Beyond the Journal and the Blog. The Technical Report for Communication in the Humanities “Amodern" 1/2013. [Accessed: 10.12.2015]

$<$ http://amodern.net/article/beyond-the-journal-and-the-blog-the-technical-report-forcommunication-in-the-humanities/ > .

Nornes, Abé Mark. “For an Abusive Subtitling” Film Quarterly 52:3 (1999): 17-34.

Venuti, Lawrence. The Translator's Invisibility: A History of Translation. London: Routledge 2008.

\section{NOTES}

1. Piotr Marecki Aleksandra Malecka present Conduit at ELO14. [Accessed: 10.12.2015]

<https://youtu.be/h-47qeqDgbM?t=1001>. 
2. Bruszewski was a member and theoretician of the legendary Film Form Workshop. He was one of the Polish pioneers of electronic literature, writing literary algorithms in the 1970s. Bruszewski produced a number of digital works on the Amiga computer, he also experimented with the idea of an augmented reality book, which he realized in the form of Big Dick, a novel combining traditional text and codes referencing an electronic library of photographs and audiovisual files. (Marecki, Pisarski 2013)

3. The meaningful title references the name of the font used in all the poems.

4. ELO Collection vol. 3 was presented during the ELO conference The End(s) of Electronic Literature in August 5-7 2015, Bergen, Norway.

5. A choice of interesting examples of localization in film may be found at <https:// www.translatemedia.com/translation-blog/localisation-in-the-film-and-tv-industries/ $>$.

6. The Renderings <http://www.nickm.com/trope_tank/renderings/>.

7. Our gratitude goes to Andrew Campana from Harvard University, for explaining this phenomenon during meetings of the Trope Tank lab at MIT.

\section{ABSTRACTS}

Translation, or adaptation, of film poems, animated or kinetic poetry and other multimedia works, poses a number of questions for translation theory and practice. Dealing with such pieces involves bringing into the target language and culture multiple formal layers of the work, not only text, but also sound, image and motion. The interplay of signifiers between the various media layers of the work amplifies the constraints to be addressed by the translator, making the concept the basic unit of translation. The English translation by Aleksandra Małecka of the 2013 online collection of 29 video poems by Katarzyna Giełżyńska was premiered at the ELO Media Arts Show in June 2014. This paper is an attempt to analyze the strategies for translating multimedia work, taking up the example of $C() n D u$ It as a case study. One of the points of departure for the analysis of the poetics of the artist's clips, which draws from the logic of logotypes, ads, and minimalist digital works. It attempts to place the new challenge within established paradigms and strategies for the translation of conceptual works of literature. Special attention is devoted to the political question of untranslatability and possible means of addressing it in the translation and curating of such projects. Even if through tackling sound, text and image, the wordplay, puns and multiple meanings are presented to the English-speaking audience, there remains the question of the context, which is particularly important in minimalist, conceptual works. The translator/curator must address the question of whether the work should be presented visibly and markedly as a translation, alongside the original and with curatorial comments on the underlying cultural tradition, or as an independent whole. An extreme response to the cultural impossibility of translation is abusive subtitling. The "abusive translations" added to the collection by Piotr Marecki constitute a performance that strongly comments on these issues. The review of possible approaches to equivalence in translating multimedia works is followed by a discussion of what this type of task entails for the description of the craft of translation and how it challenges conventional perceptions of the role of the translator. Multimedia translation often requires the collaborative effort of a number of 
specialists, posing questions about the status of the author and the translator, arguably redefining their relationship, as well as that between the original and the translated work.

INDEX

Subjects: Digital arts

Keywords: kinetic poetry, electronic literature, abusive subtitling, translation, localization

\section{AUTHORS}

PIOTR MARECKI

Assistant professor

Jagiellonian University

piotr.marecki@uj.edu.pl

ALEKSANDRA MAŁECKA

Ph.D. candidate

Jagiellonian University

aleksandra.malecka@ha.art.pl 